\title{
A comparative study of strong ground motion records from the 30 August 2013 south Tibet earthquake on the rock and soil sites of the Kathmandu valley
}

\author{
*Subeg Man Bijukchhen', Nobuo Takai', Michiko Shigefuji", Masayoshi Ichiyanagi', \\ Tsutomu Sasatani ${ }^{1}$, Sudhir Rajaure ${ }^{2}$, and Megh Raj Dhital ${ }^{3}$ \\ ${ }^{1}$ Hokkaido University, Kita-13, Nishi-8, Sapporo, Japan \\ ${ }^{2}$ Department of Mines and Geology, Nepal \\ ${ }^{3}$ Central Department of Geology, Tribhuvan University, Nepal \\ (*Email:subeg@eng.hokudai.ac.jp)
}

\begin{abstract}
The present site response study is based upon strong ground motion records from 4 seismic stations established by the Hokkaido University in the Kathmandu valley at Kirtipur, Tribhuvan University, Patan, and Thimi: one right above the bedrock and others over the lake sediments. We considered the rock-site station in Kirtipur as a reference site to quantify the amplification at sediment sites by analysing the $M b=4.9$ Southern Tibet Earthquake of 30 August 2013. The horizontal maximum velocity of $0.84 \mathrm{~cm} / \mathrm{s}$ is recorded in Thimi in contrast to $0.23 \mathrm{~cm} / \mathrm{s}$ in Kirtipur. The highest spectral amplitude at sediment sites matches with results from microtremor study. Significant amplification is seen at $0.3-1 \mathrm{~Hz}$ band at sediment sites for whole waveform whereas analysis of the S-wave part indicates amplification in the 1-2 Hz band. Surface waves in the records of sediment sites continue for quite a long time compared to that of the rock-site and records of all sites contain Rayleigh waves. Though the difference in azimuth and epicentral distance of the sites are not significant, it is observed that the initial motion at the Kirtipur site is about $0.25 \mathrm{sec}$ earlier than expected. This implies the difference in the underground body wave velocity structure of the sites. But the lack of accurate underground structure of the valley necessitates further study. For future research we will try to discuss the basin underground structure with strong ground motion data including $M b=4.4$ Gorkha Earthquake of 25 November 2014 and $M b=5.0$ Solukhumbu Earthquake of 18 December 2014.
\end{abstract}

Keywords: Earthquake, PGA, Kathmandu, Kirtipur, Strong Ground Motion

Paper Received: 20 April 2015

Paper Accepted: 04 February 2016

\section{INTRODUCTION}

The subduction of the Indian Plate under the Eurasian plate is not continuous but intermittent with periodic release of the stress causing earthquakes in the Himalayan region. Though majority of these are micro-seismic activities, the region has a history of at least seven earthquakes larger than M7.5 occurring after 1897 (Avouac et al. 2006). Kathmandu valley, the political and economic capital of Nepal (Fig. 1) is the most populated region in the country. The valley is formed by soft lake sediment of Plio-Pleistocene origin (Dhital 2015) whereas the surrounding part is formed by Pre-Cambrian to Devonian rocks (UNDP). The maximum thickness of the sediment was estimated to be $650 \mathrm{~m}$ by Moribayashi and Maruo (1980) who performed gravity measurement in the valley. The drillings carried out during the paleomagnetic study by Sakai (2001) show sediment thickness to be $550 \mathrm{~m}$ at the central part of the valley.

Large earthquakes in the past have caused significant damage as the seismic waves were amplified in soft sediments. This influence of local geology of the site on the amplification of the shaking during earthquake is termed site effect (Navarro et al. 2014). Heavy damages to infrastructures due to local site effects during earthquakes around the world are reported by
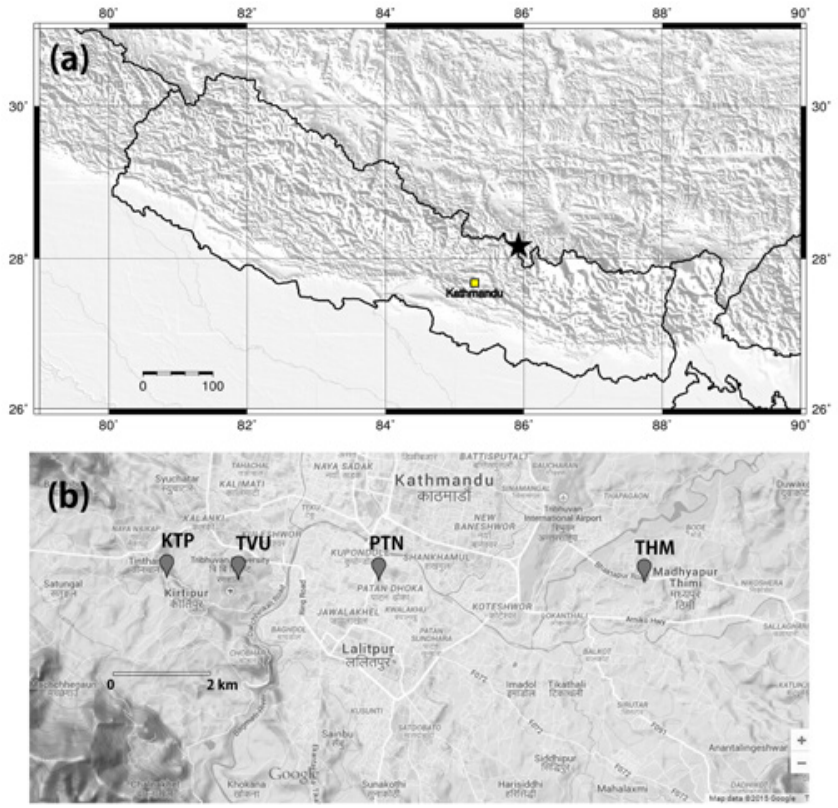

Fig. 1: (a) Location of Kathmandu valley (shown by the square) and epicenter (shown by star) of the 30 August 2013 earthquake, (b) Location of seismometers used in this study. (Base map: Google Map). 
many researchers like Pandey and Molnar 1988, Barka 1999, Özel et al. 2002, Vidal et al. 2004, Maqsood and Schwarz 2008, Navarro et al. 2008, and Cui et al. 2011. Hence, the study of the local site-effect is very important to assess the damage it might cause. This site-effect analysis is necessary for development of building codes, urban planning and overall mitigation of loss of life and property in an event of large earthquake.

There has been but few studies in the earthquake scenario of the valley in the past. JICA (2002) did an elaborative earthquake risk assessment of the valley and a research on liquefaction hazard assessment was carried out by Piya et al. (2004). Micro-tremor analysis for study of amplification effect has been carried out by Pandey (2000) and Paudel et al. (2012). The paucity of relevant data has made the research in seismic field in Kathmandu to lag behind other regions of the world which are equally as vulnerable. The study of site-effects in the whole Kathmandu valley is indeed the prime necessity as the possibility of large earthquake looms large in the Nepal Himalaya. This will need a dense network of seismic stations and large volume of strong seismic data which are both lacking at present. Nevertheless, Hokkaido University established four continuous recording three-component Mitsutoyo JEP-6A3-2 accelerometers in four different parts of the valley to study the strong ground motions. We analysed the data of 30 August 2013 South Tibetan Earthquake (Fig. 1a) to quantify and assess the site-effect of the recording sites. We also analysed the ambient noise to calculate the resonant frequency of each site and compared it with result from the above-mentioned earthquake.

\section{Station Sites and Data}

The seismic stations are situated in Kirtipur, Tribhuvan University, Pulchwok Engineering Campus, and University Grants Commission, Thimi: hereafter named as KTP, TVU, PTN and THM respectively (Fig. 1b). The site at KTP is above the bedrock whereas other stations lie above the valley sediment. We considered the KTP station as the reference and compared the response of other sites to it. The strong motion data of the 30 August 2013 earthquake with epicentre near Nepal-China border was obtained and analysed to compare the site-effects of the station sites. The magnitude of the earthquake is mentioned as $\mathrm{Ml}=6.0$ in National Seismological Centre (NSC) website and $\mathrm{Mb}=4.9$ in United States Geological Survey (USGS) website (Table 1). The mechanism for this earthquake is not available because of large azimuth gap of $37^{\circ}$. We used the earthquake information provided in the USGS website for our study. Table 2 shows distance and azimuth of the stations from the earthquake.

\section{METHODOLOGY}

The acceleration data in the three components was rotated to Radial, Transverse and Vertical components. We converted the acceleration data to velocity and obtained Fourier spectrum using Fast Fourier Transform (FFT). We checked the relation of peak ground acceleration (PGA) and peak ground velocity (PGV) with hypocentral and epicentral distance with few attenuation models.

Table 1: The parameters of the 30 August 2013 Southern Tibetan Earthquake from USGS.

\begin{tabular}{|l|l|l|l|l|l|}
\hline Date & Time & Latitude & Longitude & Depth & Magnitude \\
\hline $\begin{array}{l}\text { August } \\
2013\end{array}$ & $\begin{array}{l}17: 48 \\
\text { GMT }\end{array}$ & $26.161^{\circ} \mathrm{N}$ & $85.897^{0} \mathrm{E}$ & $\begin{array}{l}54.6 \mathrm{~km} \\
( \pm 5 \mathrm{~km})\end{array}$ & $\mathrm{Mb} 4.9$ \\
\hline
\end{tabular}

Table 2: Distance and Azimuth of the earthquake from the stations.

\begin{tabular}{|l|l|l|l|l|}
\hline Station & \multicolumn{1}{|c|}{$\begin{array}{c}\text { Site } \\
\text { condition }\end{array}$} & $\begin{array}{c}\text { Epicentral } \\
\text { Distance } \\
(\mathbf{k m})\end{array}$ & $\begin{array}{c}\text { Epicentre- } \\
\text { to-station } \\
\text { azimuth }\end{array}$ & $\begin{array}{c}\text { Hypocentral } \\
\text { distance }(\mathbf{k m})\end{array}$ \\
\hline KTP & Rock & 81.24 & $229.34^{\circ}$ & 98.36 \\
\hline THM & Soil & 80.10 & $228.59^{\circ}$ & 97.38 \\
\hline PTN & Soil & 77.86 & $227.09^{\circ}$ & 95.56 \\
\hline THM & Soil & 73.83 & $224.03^{\circ}$ & 92.36 \\
\hline
\end{tabular}

The site effects were then computed by using spectral ratio method. Spectral ratio is the ratio of spectral amplitude of a site to that of the reference site for the same earthquake. This method, first proposed by Borcherdt and Gibbs (1970), considers a reference site with negligible site response and an interstation distance smaller than epicentral distance (Field and Jacob 1995). In the present study we assumed the KTP site as the reference site with negligible site response. We calculated the spectral ratio for TVU, PTN, and THM with reference to KTP. We chose $2.5 \mathrm{sec}$ section of S-wave and also calculated $\mathrm{S}$-wave spectral ratio.

We have selected $286.72 \mathrm{sec}$ of microtremor record and then calculated $\mathrm{H} / \mathrm{V}$ spectral ratio for each of the four sites to compute the resonant frequency of respective site. $\mathrm{H} / \mathrm{V}$ ratio method is the ratio of spectral amplitude of mean horizontal direction to that of vertical direction. The record was selected for night time to avoid spurious and anthropogenic noises. The H/V ratio was calculated for every $20.48 \mathrm{sec}$ sections and averaged over 14 sections to minimise the noise: the similar method used by Paudel et al. (2012) during their microtremor study in the valley. We then compared the resonant frequency from the $\mathrm{H} / \mathrm{V}$ spectral ratio of microtremor record and that from classical spectral ratio of the earthquake record. 


\section{OBSERVATION}

The earthquake occurred at 17:48 UTC (23:33 hrs Local time) and was felt by many people in the valley. The maximum horizontal peak ground velocity (PGV) recorded was 0.84 $\mathrm{cm} / \mathrm{s}$ in Transverse component of THM in contrast to $0.23 \mathrm{~cm} / \mathrm{s}$ in same component of KTP (Fig. 2). The velocity waveforms indicate high PGV values for TVU and THM than that of the PTN. The waveforms in soil sites also show long period waves that continue for quite a long time when compared to that of rock site.

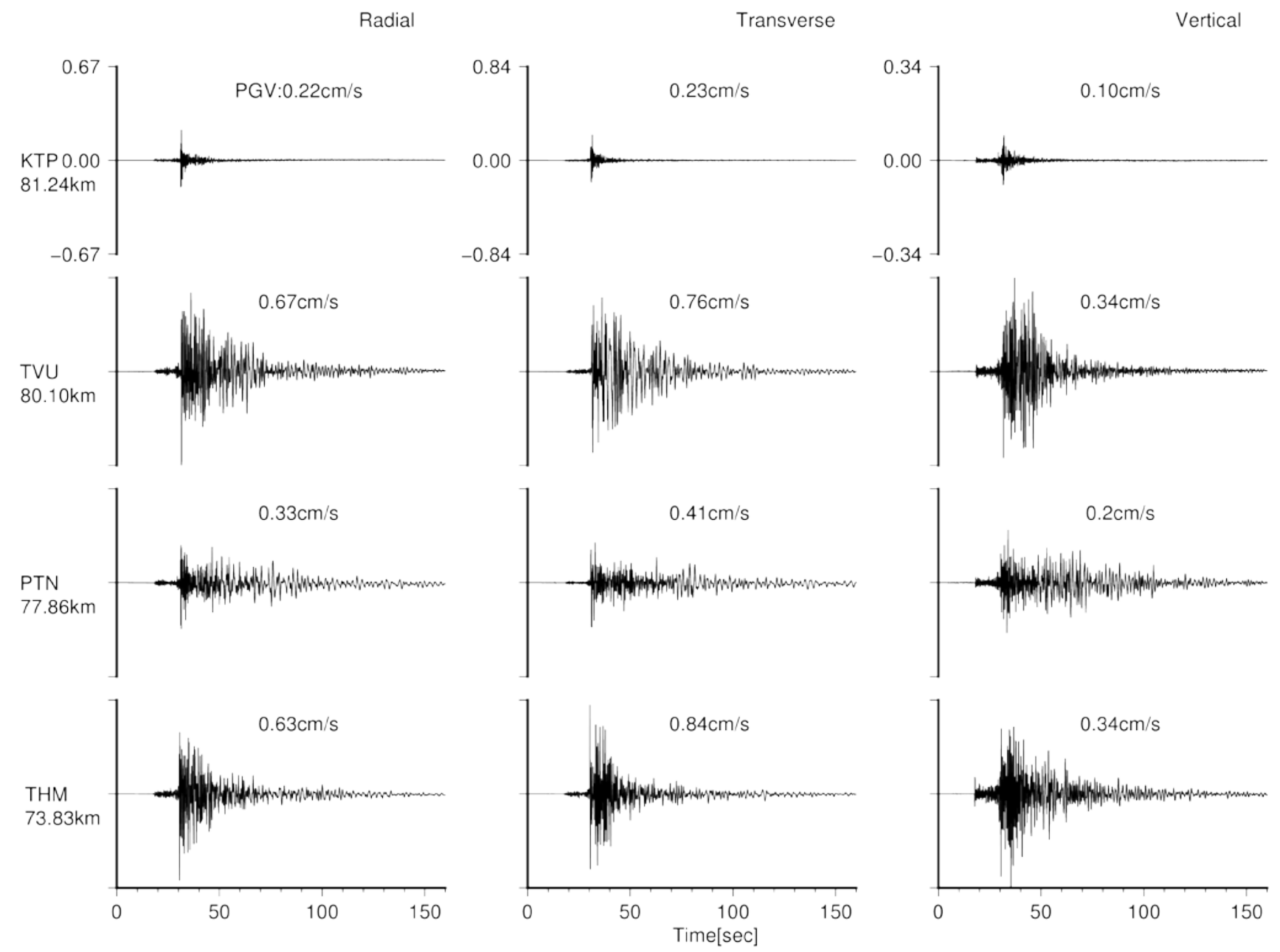

Fig. 2: Three component velocity waveform of the earthquake from all four stations.

We used the PGA and PGV to check the validity of different attenuation models to this earthquake. We compared the attenuation models of Boore et al. (1997), Abrahmson and Silva (1997), Campbell (1997), and Si and Midorikawa (1999). The Si and Midorikawa model was the best fit for both PGA and PGV values of the earthquake (Fig. 3). For the comparison, we considered the source of this earthquake as a normal fault. Avouac (2003) and Bollinger et al. (2004) indicated that the maximum compressive stress in the Himalaya which is north-south oriented below 3,500 m leading to thrust changes to vertical above $3,500 \mathrm{~m}$. The focal mechanisms of past earthquakes above this contour of 3,500 $\mathrm{m}$ indicate east-west extensions leading to normal faulting. The moment magnitude Mw was also considered to be same as Mb based on the relation given by Kanamori (1983). 

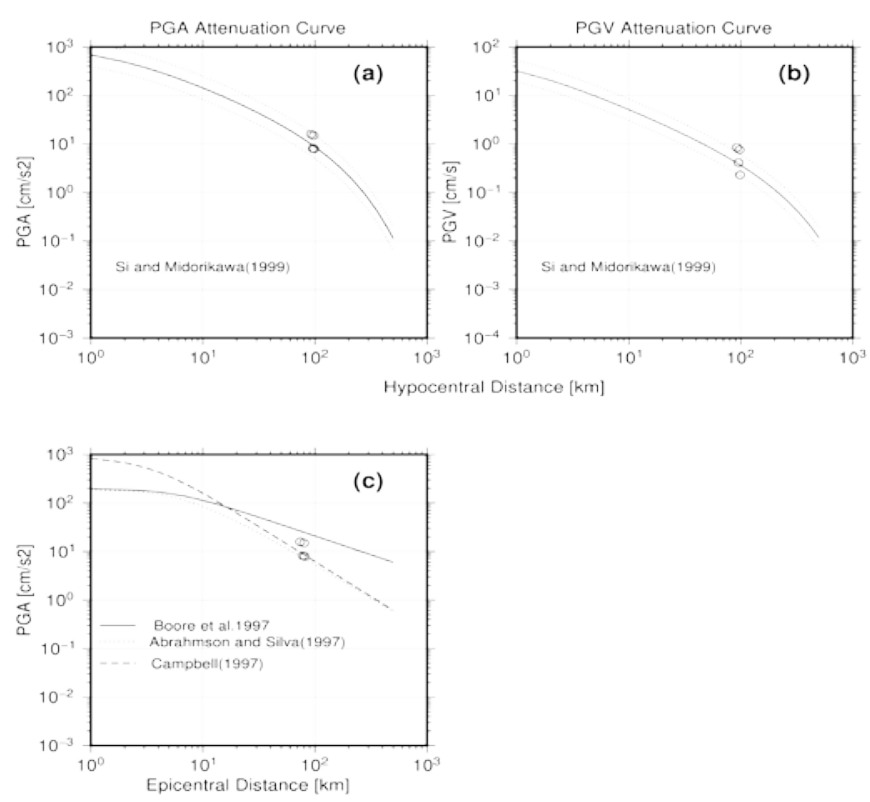

Fig. 3: (a) Relation between hypocentral distance and PGA values and (b) hypocentral distance and PGV values follows the Si and Midorikawa (1999) Attenuation formula. The dotted lines are the standard deviation of the attenuation formula; (c) Relation between epicentral distance and PGA compared with various attenuation formulas.

If we take a look at the spectrum of the whole signal (160 sec) in Fig. 4, we can see that in $0.2-0.4 \mathrm{~Hz}$ band in soil site spectrum, the curve illustrates a steep slope which is not observed in the curve of KTP. This indicates the dominance of $0.3-1 \mathrm{~Hz}$ waves in the soil sites than in KTP. The TVU site shows peaks at 0.4 and $1.0 \mathrm{~Hz}$ and PTN and THM have peak amplitudes at $0.3 \mathrm{~Hz}$.
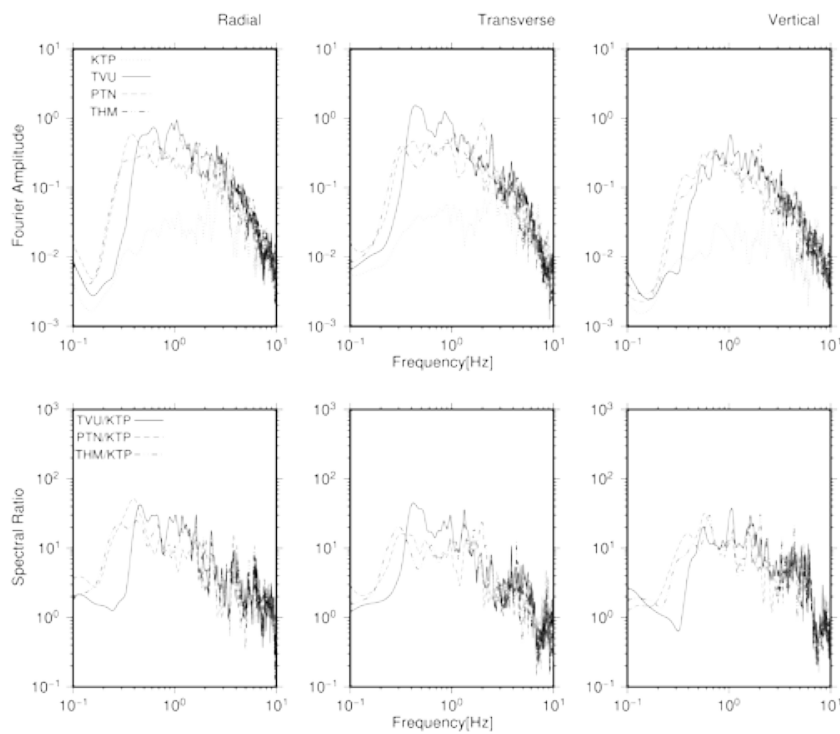

Fig. 4: Fourier spectrum and Spectral ratio for $160 \mathrm{sec}$ of earthquake record. The top three figures are the Fourier spectrum in three components and lower three are spectral ratio in respective components.
We plotted the particle motion for every 2 second from 44-54 sec section of the band-pass-filtered waveform (0.2-1 $\mathrm{Hz}$ ). The motion plots (Figs. 5 and 6) in V-R (vertical-radial) direction show the retrograde motion indicating presence of Rayleigh waves.
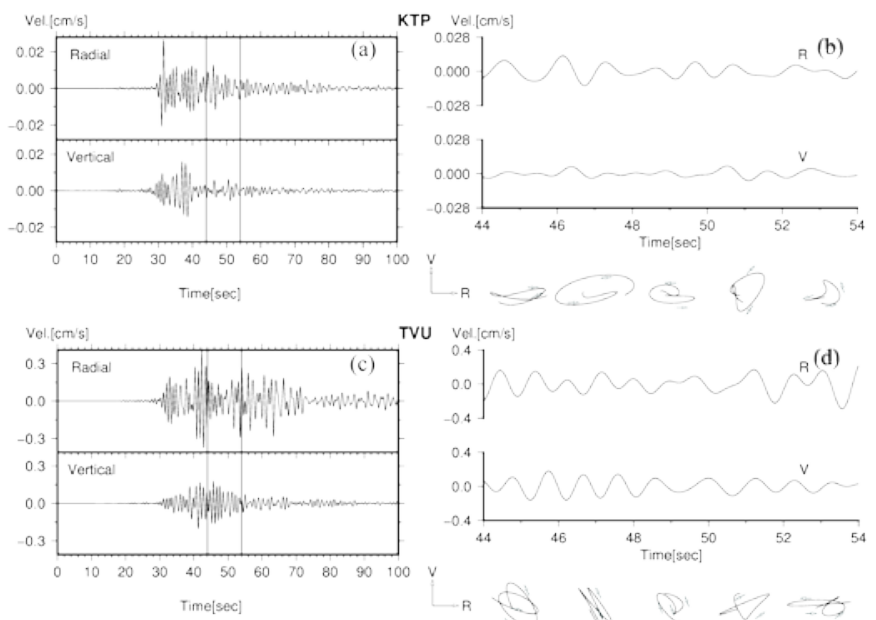

Fig. 5: Particle motion plot in V-R direction: (a) band-passfiltered (0.2-1 Hz) velocity waveform of KTP indicating section of 44-54 sec and (b) particle motion plot for KTP every 2 sec. (c) and (d) are the similar figures for TVU. The small arrows indicate the direction of motion.
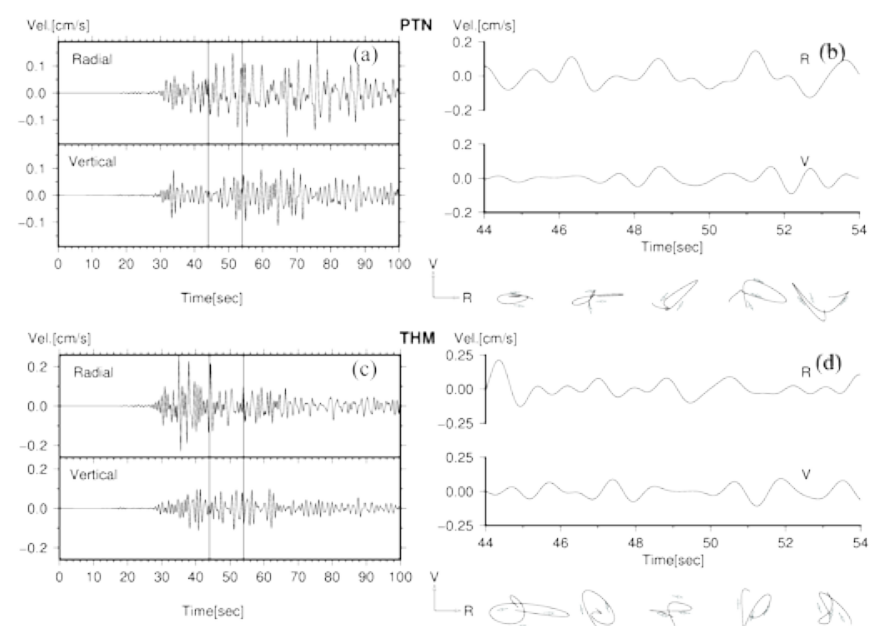

Fig. 6: Particle motion plot in V-R direction: (a) band-passfiltered (0.2-1 $\mathrm{Hz})$ velocity waveform of PTN indicating section of 44-54 sec and (b) particle motion plot for PTN every 2 sec. (c) and (d) are the similar figures for THM. The small arrows indicate the direction of motion.

The resonant frequency calculated using the $\mathrm{H} / \mathrm{V}$ ratio method in the microtremor records are $0.43 \mathrm{~Hz}, 0.35 \mathrm{~Hz}$, and $0.29 \mathrm{~Hz}$ for TVU, PTN, and THM respectively (Fig. 7), which matches the peaks in the spectral ratios calculated by classical spectral ratio method (Fig. 4). The resonant frequency at the rock site KTP at $3.22 \mathrm{~Hz}$ is most likely due to the building as the spectral ratio of rock site should have been devoid of any prominent peaks. 

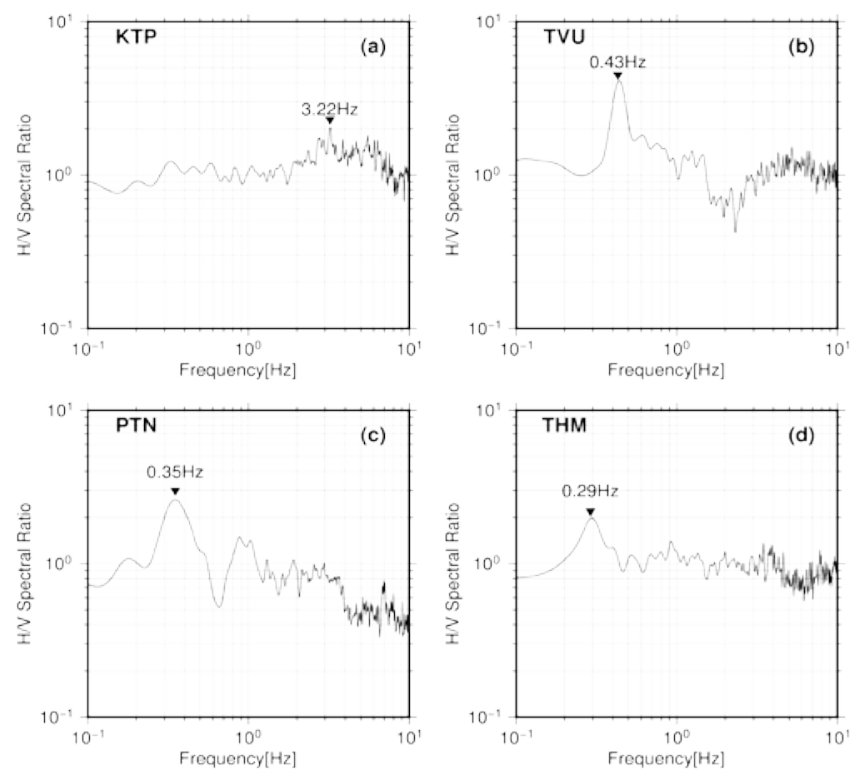

Fig. 7: Resonant frequency of the sites determined by H/V (Horizontal to Vertical) spectral ratio of microtremor records.

The spectral ratio of S-wave is shown from $0.1 \mathrm{~Hz}$ to $10 \mathrm{~Hz}$ range only. We considered the P-coda as the noise and checked SNR with the S-wave part and found SNR to be highest in the frequency band of 1-10 Hz. Analysis of the S-wave part indicates a spectral ratio of 2-10 in the 1-2 Hz band in the sediment sites (Fig. 8) in both of the horizontal components. The maximum amplification is in TVU whereas the PTN site shows less amplification. We can see another peak at 4-5 Hz band which probably is the resonant frequency of the buildings where the instruments are housed.
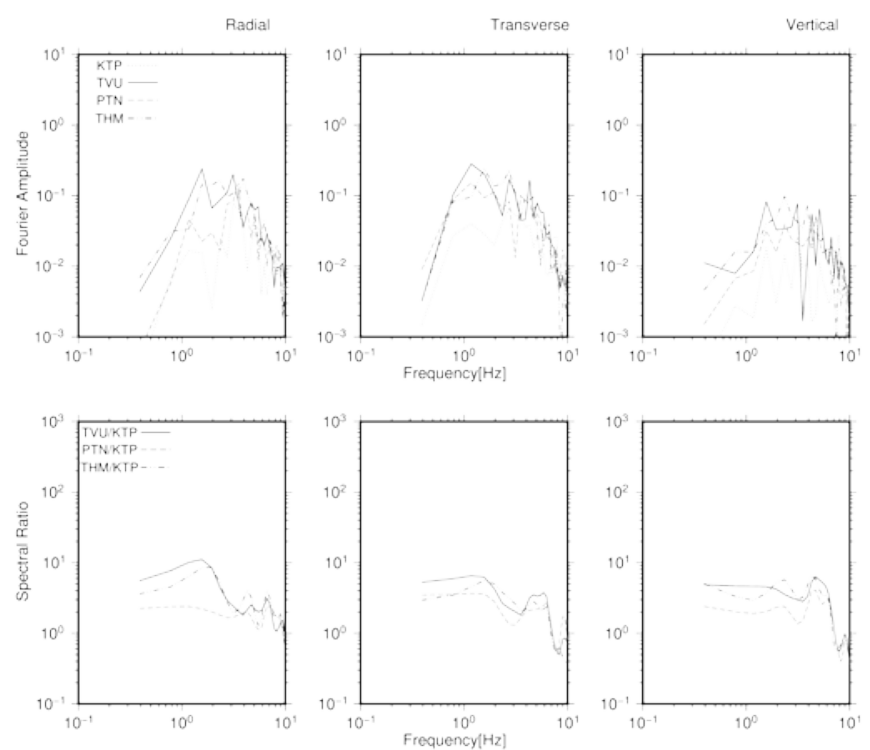

Fig. 8: Fourier Spectrum and Spectral ratio of $2.5 \mathrm{sec}$ S-wave part. The upper three figures are Fourier spectral amplitude and the lower three are spectral ratio amplitude.
Even though the difference in azimuth and epicentral distance of the sites is not significant, it is observed that the initial motion of S-wave at the KTP is a quarter of second earlier than expected. This implies the difference in the underground body wave velocity structure of the sites. Similar difference in S-wave arrival in thick sediment deposit was also reported in Adapazari basin in Turkey by Özel and Sasatani (2004).

\section{DISCUSSION AND CONCLUSIONS}

The information regarding the location, origin time, depth and magnitude were obtained from websites of United States Geological Survey www.earthquake.usgs.gov (last accessed March 2015) and National Seismological Centre, Nepal www. seismonepal.gov.np (last accessed March 2015). The location map of the stations was drawn on the base map from Google Map, www.maps.google.com (last accessed March, 2015).

The results in the study are preliminary as we lack the proper density of earthquake stations and accurate underground structure of Kathmandu valley. We need to study data of several strong motion data recorded over a large area to reach a definite conclusion about local site effects on amplification of seismic waves in the whole valley. Nevertheless, this study is a small step towards the future researches. In the meantime we are working in estimation of underground structure with the strong ground motion data including $M b=4.4$ Gorkha Earthquake of 25 November 2014 and $M b=5.0$ Solukhumbu Earthquake of 18 December 2014 in these sites. We performed a comparative study of site-effects in four sites of the Kathmandu valley using strong ground motion records of an earthquake with epicentre around $80 \mathrm{~km}$ north-east from the valley. The earthquake with $\mathrm{Mb} 4.9$ follows the attenuation relation given by Si and Midorikawa (1999). We employed the spectral ratio method considering the rock site at Kirtipur as the reference site. This analysis indicates that the soil sites demonstrate remarkable amplification of the waves in frequency $0.3-1 \mathrm{~Hz}$. We also carried out the micro-tremor analysis using the same instruments which show the resonant frequency ranging from 0.29 to $0.43 \mathrm{~Hz}$. The S-waves on the other hand are amplified 2-10 times in 1-2 $\mathrm{Hz}$ band.

Since the epicentral distance and epicentre-to-station azimuth is similar for the stations, the source radiation pattern should be almost the same. But, we observed that the waveforms recorded at these stations significantly vary with each other. This difference is due to the $3 \mathrm{D}$ velocity structure of the valley.

The quick arrival of seismic wave in the rock site of KTP suggests that the thick sediment under the soil sites delayed the waves in other sites and there is clearly a difference in the underground body wave velocity structure. The records in soil sites show that long period waves continue for a long time and also contain Rayleigh waves which was determined by particle motion plot. 
The significant amplification in 0.3-1 Hz in sediment sites means the waves in that particular band is highly amplified. The buildings having fundamental frequency in the same band will suffer intensified vibrations causing damage during big earthquakes. The recent years have seen the increase in medium rise buildings in the valley which might add to the woes unless proper measures are taken. Regrettably, lack of proper study resulting in absence of specific building code has already made Kathmandu susceptible to earthquake damages.

\section{ACKNOWLEDGEMENTS}

We would like to thank the Government of Japan for providing the MEXT Scholarship without which this study may not have been possible. We also like to acknowledge our colleagues of the Laboratory of Urban Disaster Management, Hokkaido University who helped us during the study.

\section{REFERENCES}

Abrahamson, N. A. and Silva, W. J., 1997, Empirical response spectral attenuation relations for shallow crustal earthquakes. Seism. Res. Lett., v. 68 (1), pp. 94-127.

Avouac, J. P., 2003, Mountain building, erosion, and the seismic cycles in the Nepal Himalaya. Adv. Geophys., v. 46 , pp. 1-80.

Avouac, J. P., Ayoub, F., Leprince, S., Konca, O., and Helmberger, D. V., 2006, The 2005, Mw 7.6 Kashimir earthquake: Sub-pixel correlation of ASTER images and seismic waveforms analysis. Earth and Planetary Sci. Lett., v. 249, pp. 514-528.

Barka, A., 1999, The 17 August 1999 Izmit earthquake. Science, v. 285, pp. 1858-1859.

Bollinger, L., Avouac, J. P., Cattin, R., and Pandey, M. R., 2004, Stress build-up in the Himalaya. Jour. Geophys. Res., v. 109 (B11405). doi:10.1029/2003JB002911.

Boore, D., Joyner, W., and Fumal, T. E., 1997, Equation for estimating horizontal response spectra and peak acceleration from western North American earthquakes: A summary of recent work. Seism. Res. Lett., v. 68 (1), pp. 128-153.

Borcherdt, R. D. and Gibbs, J. F., 1970, Effects of local geological conditions in the San Francisco Bay region on ground motions and the intensities of the 1906 earthquake. Bull. Seismol. Soc. Am., v. 66, pp. 467-500.

Campbell, K. W., 1997, Empirical near-source attenuation relationships for horizontal and vertical components of peak ground acceleration, peak ground velocity, and pseudo-absolute acceleration spectra. Seism. Res. Lett., v. 68 (1), pp. 154-179.

Cui, P., Chen X. Q., Zhu, Y. Y., Su, F. H., Wei, F Q., Han, Y. S., Liu, H. J., and Zhuang, J. Q., 2011, The Wenchuan earthquake (May 12, 2008), Sichuan Province, China, and resulting geohazards. Nat. Haz., v. 56(1), pp. 19-36.

Dhital, M. R., 2015, Geology of Nepal Himalaya. Springer International Publishing, Switzerland, pp. 448-449, doi 10.1007/978-3-319-02496-7.

Field, E. H. and Jacob K. H., 1995, A comparison and test of various site-response estimation techniques, including three that are not reference-site dependent. Bull. Seismol. Am., v. 85, pp. 1127-1143.

Japan International Cooperation Agency (JICA), 2002, The study of earthquake disaster mitigation in the Kathmandu valley Kingdom of Nepal - Final Report, v. III, 76 p.

Kanamori, H., 1983. Magnitude scale and quantification of earthquakes. Tectonophysics, v. 93(3/4), pp. 185-199.

Maqsood, S. T. and Schwarz, J., 2008, Analysis of building damage during the 8 October 2005 earthquake in Pakistan. Seism. Res. Lett., v. 79(2), pp. 163-177.

Moribayashi, S. and Maruo, Y., 1980, Basement topography of the Kathmandu Valley, Nepal- an application of gravitational method to survey of a tectonic basin in the Himalayas. Jour. Japan Soc. Engg. Geol., v. 21(2), pp. 80-87.

Özel, O. and Sasatani, T., 2004, A site effect study of Adapazari basin, Turkey, from strong- and weak-motion data. Journal of Seismology, v. 8, pp. 559-572.

Özel, O., Cranswick, E., Meremonte, M., Erdik, M., and Safak, E., 2002, Site effects in Avcilar, west of Istanbul, Turkey, from strong- and weak-motion data, v. 92(1), pp. 499508.

Pandey, M. R., 2000, Ground response of Kathmandu valley on the basis of microtremors. Conference: 12th World Conference on Earthquake Engineering, Auckland.

Pandey, M. R. and Molnar, P., 1988, The distribution of intensity of the Bihar-Nepal earthquake of 15 January 1934 and bounds on the extent of the rupture zone. Jour. Nepal Geol. Soc., v. 5(1), pp. 22-44.

Paudel, Y. R., Yatabe, R., Bhandary, N. P., and Dahal, R. K., 2012, A study of local amplification effect of soil layers on ground motion in the Kathmandu valley using microtremor analysis. Earthq. Eng. \& Eng. Vib., v. 11, pp. 257-268.

Piya, B. K., van Westen, C. J., and Woldai, T., 2004, Generation of geological database for the Liquefaction hazard assessment in Kathmandu valley. Conference: Int. Symp. on Geo-dist., Info. Mgmt. and Protectn. of World Heritage Sites, pp. 9-25.

Sakai, H., 2001, Stratigraphic division and sedimentary facies of the Kathmandu Basin Group, Central Nepal. Jour. Nepal Geol. Soc., v. 25 (Sp. Issue), pp. 19-32.

Si, H. and Midorikawa, S., 1999, Attenuation relations for peak ground acceleration and velocity considering effects of fault type and site condition. Jour. of Struct. Constrc. Eng. (Transactions of AIJ), v. 523, pp. 63-70 (In Japanese).

UNDP, 1981 Geology of Kathmandu area and central Mahabharat range, Nepal Himalaya. HMG/UNDP Mineral Exploration Project, Kathmandu, 64 p.

Vidal, F., Mourabit, T., Navarro, M., Enomoto, T., and Feriche, M., 2004, A preliminary account on the intensity and structural damage on the 24 February 2001 Al Hoceima (Morocco) earthquake. XXIX General Assembly of the European Seismological Commission, Postdam. 